\title{
Improvement In MAODV Protocol Using Location Based Routing Protocol
}

\author{
Sharnjeet kaur ${ }^{1}$ and Manpreet kaur ${ }^{2}$ \\ ${ }^{1}$ Mtech student, ECE Department, Yadavindra College of Engineering, Talwandi Sabo \\ ${ }^{2}$ Assistant Professor, ECE Department, Yadavindra College of Engineering, Talwandi Sabo
}

\begin{abstract}
Energy saving is difficult in wireless sensor network (WSN) due to limited resources. Each node in WSN is constrained by their limited battery power for their energy. The energy is reduced as the time goes off due to the packet transmission and reception. Energy management techniques are necessary to minimize the total power consumption of all the nodes in the network in order to maximize its life span. Our proposed protocol Location based routing (LBR) aimed to find a path which utilizes the minimum energy to transmit the packets between the source and the destination. The required energy for the transmission and reception of data is evaluated in MATLAB. LBR is implemented on Multicast Ad hoc On Demand Distance Vector Routing Protocol (MAODV) to manage the energy consumption in the transmission and reception of data. Simulation results of LBR show the energy consumption has been reduced.
\end{abstract}

\section{Introduction}

Wireless Sensor Network (WSN) is a recent and popular technology for the 21 st century. Wireless sensor networks are likely to be broadly deployed in the future because they considerably extend the ability to monitor and manage the physical environment from remote locations. Such networks are formulated of a large number of sensor nodes, which are broadly deployed either inside the phenomenon or very close to it. These small sensor nodes consist of sensing, data processing and communicating components. Some of the application areas are health, military and security. Wireless sensor networks have unique characteristics like energy computation and storage constraints which present many challenging issues in the development and application of Wireless sensor networks. Wireless sensor network faces considerable problems in data processing, communication and sensor node management. This is because of uneven conditions like an uncertain and dynamic environment along with energy constraints. The Wireless sensor network poses additional challenges in the field of network routing protocols, energy efficiency, sensor node assessment strategies and energy models. There is required to analyze the performance of existing routing protocols, in order to grow new protocols that can extend network lifetime as well as can be easily manageable on network of different sizes.

Multicast ad hoc distance vector (MAODV) is one of routing protocols used for routing but this protocol is not energy efficient. This consumes high energy and power consumption. This paper proposes a Location Based protocol using the dijkstra algoritm and the estimated distance information among the sensor nodes and find out the shortest path between the source node and destination node with low cost. Location based routing takes location information into account while determining routes. Each node is aware of its geographical position (by the use of GPS), and this knowledge is exploited to create routes. It uses the shortest path position estimation between source and destination nodes in Wireless Sensor Networks.

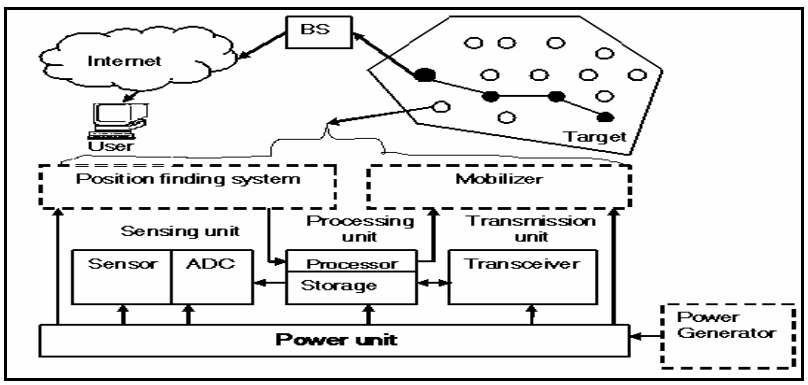

Figure 1. Structural view of sensor network

The focus of the paper is shortest path position estimation between source and minimize the energy consumption. The paper is organized as follows. Section 2 presents the previous work of energy consumption problems in wireless sensor networks. In section 3 the MAODV is discussed. Proposed method has been discussed in section 4. In section 5 Simulation Results of the paper has been discussed. In section 6 Conclusion and Future work, where the future challenges and directions to improve energy consumed in WSN technology are described.

\footnotetext{
${ }^{1}$ Sharnjeet kaur: sharankaur044@gmail.com
} 


\section{Multicast Ad Hoc Distance Vector Routing (MAODV)}

MAODV consists of two basic routing operations such as route discovery and maintenance. In MAODV, when a source node sends a RREQ for a multicast group; generally it receives more than one reply. The source node has the record of the received route with the greatest sequence number and shortest hop count to the most near member of the multicast tree for a selected period of time, and disregards other routes. At the last of this period, it enables the selected next hop in its multicast route table, and unicast an activation message (MACT) to this selected next hop [11]. The next hop, on receiving this message, makes able the entry for the source node in its multicast route table. If the present node is a member of the multicast tree, it does not broadcast the message any further. However, if this node is not a member of the multicast tree, it will have received one or more RREPs from its neighbours. This method continues until the node that initiated the RREP (member of tree) is reached. The activation message makes sure that the multicast tree does not have multiple paths to any tree node. Nodes just forward data packets along activated routes in their multicast route tables. The multicast group leader is responsible for maintenance the multicast group sequence number and propagating this number to the multicast group. This is done through a Group Hello message. The Group Hello have increments in that indicate the multicast group IP address and sequence numbers of all multicast groups for which the node is the group leader. Nodes make use of the Group Hello information to update their request table. Then optimal path is established.

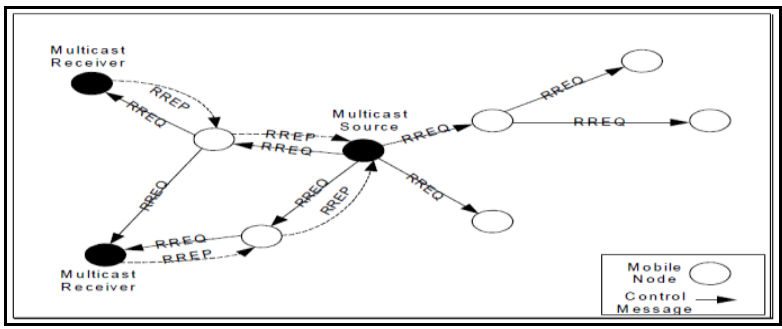

Figure 2. MAODV Algorithm

The network is deployed with the finite number of nodes. These nodes are free to move independently. The topology of network changes accordingly. Data is transferred from source to destination.

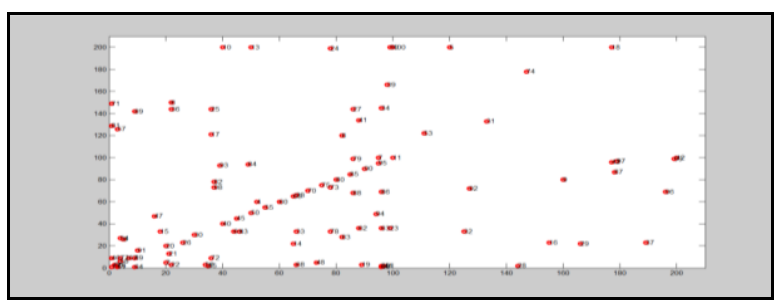

Figure 3. Node Deployment in MAODV

\section{Proposed Work}

Routing algorithms based on geographical location is an important research subject in the Wireless sensor network. They use location information to guide routing discovery and maintenance as well as packet forwarding, thus enabling the best routing to be selected, reducing energy consumption and optimizing the whole network. Location based routing protocol is very important in Wireless sensor network. It maintains a minimum energy network for wireless networks by utilizing low power GPS. This protocol can be used for mobile networks but it is best suited for sensor networks. This is because sensor networks are not mobile.

Location based routing takes location information into account while determining routes. Each node is aware of its geographical position (by the use of GPS), and this knowledge is exploited to create routes. Location based routing can be considered as a special case of context aware routing with the location being the context information that is used. LBR makes use of location information to reduce routing overhead. With the availability of GPS, it is possible for a mobile host to know its physical location. So Location-based routing is a system of rules to varying degrees of complexity dictating where inbound telephone calls from various locations are routed to. Thus, LBR is an on-demand or reactive routing protocol. It tries to search for a path from the source to the destination by broadcasting RREQ packets it its neighbors, similar to on demand routing.LBR has the protocol has many protocols which are based on location ability.

\subsection{Problem implementation using LBR}

Main problem in MAODV is that it consumes very high energy and battery. To improves MAODV another routing protocol LBR into this method. The locationbased routing protocols compute routing paths based on the location of nodes. These protocols use node's location information, instead of links information for routing. They are also known as position based routing protocols. [9]In position based routing protocols, it is supposed that the packet source node has position information of itself and its neighbours and packet destination node. Coming to the way the LBRs GPRS protocol works, Packets in the GPSR protocol are marked by their originator with their destinations location. Forwarding in this way, the destination is reached in successively close geographic hops. In proposed approach only those nodes participate in route discovery process which has coordinates moving towards destination node. And the selection process is same as on demand routing protocol. LBR selects route using GPS. It contacts all the nodes in between the route coordinates. It takes all the nodes which come under the coordinates. Thus the energy wasted in MAODV can be recovered by this method. 


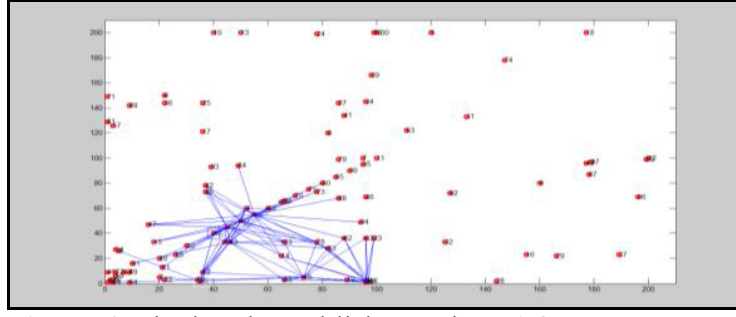

Figure 4. Final Path establishment in MAODV

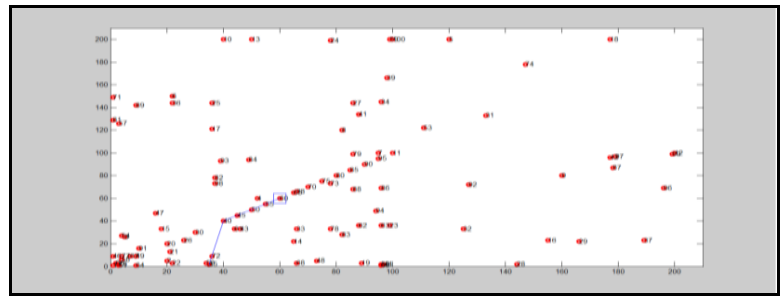

Figure 5. Final Path establishment in LBR

\section{Experimental Results}

In order to perform and calculate the impact of link failure in ADHOC network, the AODV implementation is modified using the MATLab tool.

Table 5.1 Simulation Parameters

\begin{tabular}{|c|c|}
\hline $\begin{array}{c}\text { SIMULATION } \\
\text { PARAMETERS }\end{array}$ & VALUES \\
\hline Simulator & MATLAB \\
\hline Simulation area & $200 \mathrm{~m} \times 200 \mathrm{~m}$ \\
\hline Protocol used & MAODV,LBR \\
\hline No. of Nodes & 100 \\
\hline Initial energy & $0.5 \mathrm{~J}$ \\
\hline Transmitting power & $0.175 \mathrm{~mW}$ \\
\hline Receiving power & $0.145 \mathrm{~mW}$ \\
\hline Node placement & Random \\
\hline Radio range & $40 \mathrm{~m}$ \\
\hline Tool & Matlab13 \\
\hline
\end{tabular}

\subsection{Energy consumption graph}

Energy consumption is defined as the amount of energy consumed by nodes in the network through communication and processing. So, the total energy consumed, given as ET, can be calculated by adding all energy consumed by each nodes, $\mathrm{n}$, for transmission (TX), received (RX) and processing throughout the simulation time.

$$
\mathrm{E}_{\mathrm{T}}=\sum_{\mathrm{i}=1}^{\mathrm{n}}\left(\mathrm{E}^{\mathrm{n}}{ }_{\mathrm{tx}}+\mathrm{E}^{\mathrm{n}} \mathrm{rx}\right)
$$

Energy consumption graph is between time stamp and energy consumed. In case of MAODV network is consuming $0.04226 \mathrm{~J}$ when sending data source to destination. And in case of LBR the energy consumption is reduced to $0.00062 \mathrm{~J}$.

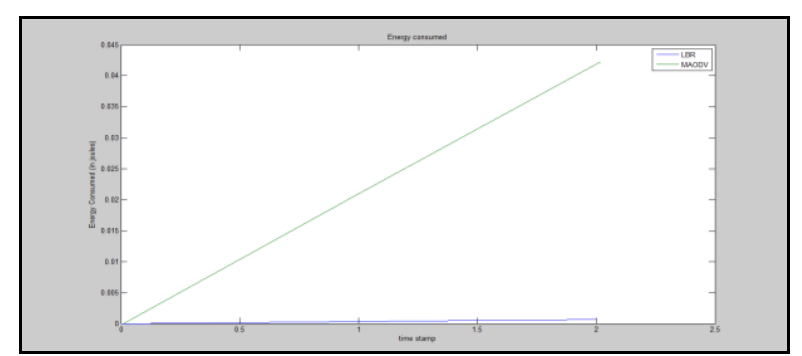

Figure 6. Comparison of energy consumption using MAODV and MAODV with LBR

\subsection{Time duration for path selection graph}

Time duration is total time for finding the path from source to destination. It calculates the time when sender sends RRQ to destination. This section shows comparison between is the time consumption for path selection for LBR and MAODV.

$$
\mathrm{e}=\text { cputime- } \mathrm{t}
$$

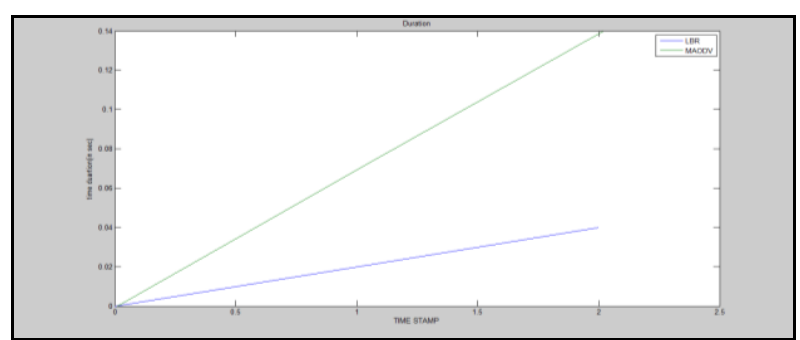

Figure 7. Comparison of time duration using MAODV and MAODV with LBR

\subsection{End to End delay graph}

End to end delay is average time taken by a data packet to arrive in the destination.

End to end $=\mathrm{N}\left[\mathrm{d}_{\text {trans }}+\mathrm{d}_{\text {prop }}+\mathrm{d}_{\text {proc }}\right]$

Graph shows the comparison of both with and without using LBR. MAODV takes $15.81 \mathrm{sec}$ of delay while LBR takes only $0.3256 \mathrm{sec}$.

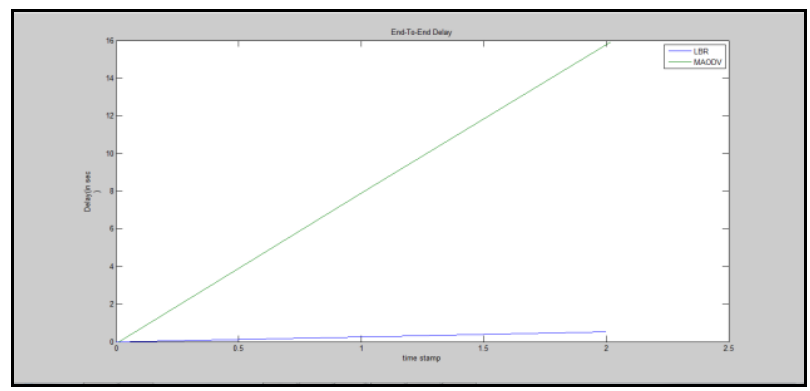

Figure 8. Comparison of End to End delay using MAODV and MAODV with LBR 


\subsection{Nodes used graph}

These are total no of nodes which are participating in the communication process for different routing protocols. From the result it shows that MAODV is consuming more no of nodes. MAODV is using 58 nodes in routing process while LBR technique is using only 10 nodes.

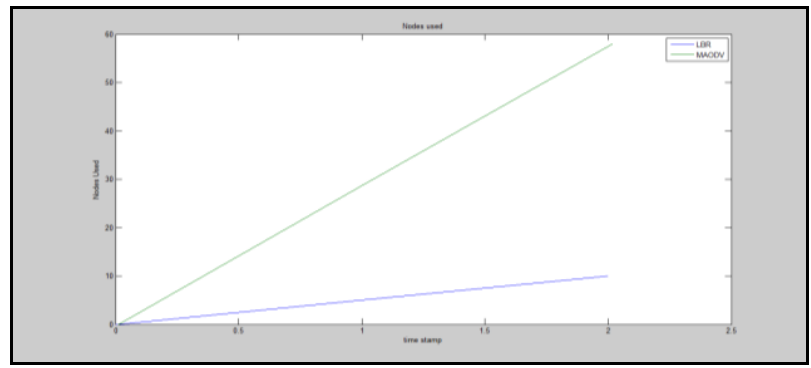

Figure 9. Comparison of nodes used using MAODV and MAODV with LBR

\subsection{Residual energy graph}

It is the energy remained in the network is residual energy. It is calculated by:

Energy remained =Total energy of the network-energy consumed.

The energy remained in the network is $49.5774 \mathrm{~J}$ in case of MAODV. For LBR it is 49.9938J.

From the results it shows that LBR has more remaining energy as compared to MAODV.

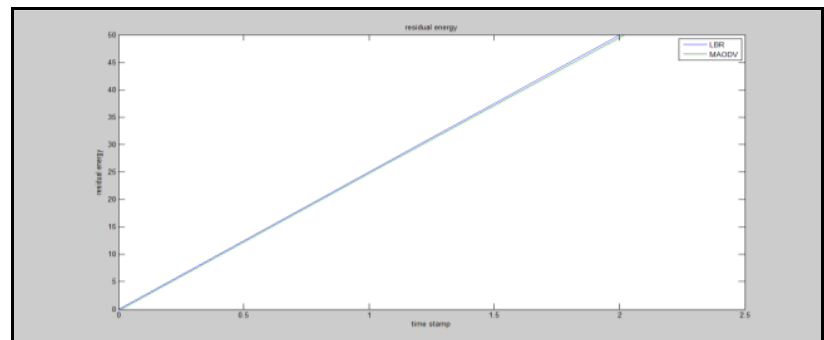

Figure 10. Comparison of Residual energy using MAODV and MAODV with LBR

\subsection{Node battery consumption graph}

It is energy consumed by nodes in the process. In LBR nodes are consuming very less energy as compared to MAODV. This shows how much battery is consumed.

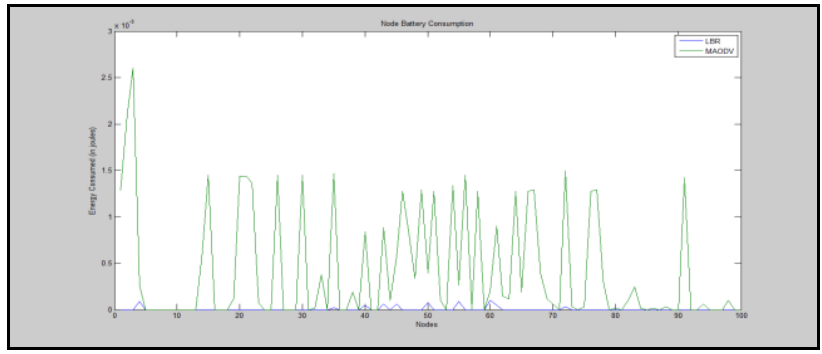

Figure 11. Comparison of battery consumption using MAODV and MAODV with LBR

\section{Conclusion}

MAODV protocol is used to find out the path of the data transfer. But simple MAODV has the problem of energy consumption. This technique takes lot of battery consumption and also it is very time consuming. More no of nodes are consumed in this process. Enhancement in MAODV is required to overcome the problems so that consumption of energy can reduced in data transfer from source to destination. In my proposed work, enhancement in MAODV concept is important. The objectives listed in the problem statement have been carried out properly in my work. I have added LBR protocol to MAODV protocol. This work helps in reducing the problem of energy and power consumption. Also improve the residual energy and delay.

The energy and power consumption are the major issues in wireless networks. A lot of research has to be needed to reduce energy in wireless networks. More efficient protocols will be used to reduce energy and power which will provide great performance.

\section{References}

1. AZZEDINE BOUKERCHE, "Performance Evaluation of Routing Protocols for Ad Hoc Wireless Networks", Mobile Networks and Applications 9, pp.333-342, (2004).

2. Abid Ali Minhas, Fazl-e-Hadi, Danish Sattar, KashifMustaq and S. Ali Rizvi,"Energy Efficient Multicast Routing Protocols for Wireless Sensor Networks",World congress on information and technology, pp.178-181, (2011).

3. B.Baranidharan, B.Shanthi, "A Survey on Energy Efficient Protocols for Wireless Sensor Networks", International Journal of Computer Applications (0975 - 8887) Vol.11, No.10, pp.35-40, December (2010).

4. Charles E Perkins, Elizabeth M Royer, "Adhoc OnDemand Distance Vector Routing”,Mobile Computing Systems and Applications, 2000. Proceedings, pp.1-11.IEEE, (2000)

5. Daehee Kim, Sejun Song,and Baek-Young Cho,"Energy-Efficient Adaptive Geosource Multicast Routing for Wireless Sensor Networks, Hindawi Publishing Corporation Journal of Sensors, pp.1-14, (2013)

6. David B. Johnson ,David A. Maltz ,Josh Broch, "DSR: The Dynamic Source Routing Protocol for Multi-Hop Wireless Ad Hoc Networks ," Mobile Computing, T. Imielinski and H. Korth, Eds, vol. 5

7. Emad Felemban,"MMSPEED: Multipath MultiSPEED Protocolfor QoS Guarantee of Reliability and Timeliness in Wireless Sensor Networks", IEEE Transactions On Mobile Computing, Vol. 5, No. 6, pp.738-754, (2006)

8. Heng Liu, Yan-tao Liu, Ting Yan,"Making Ondemand Multicast Routing Protocol Aware of Energy in Wireless Sensor Networks", pp.1-4, IEEE , (2008) 
9. Hyuntae Cho and Yunju Baek,"Location-Based Routing Protocol for Energy Efficiency in Wireless Sensor, pp. 622 - 631, IEEE , (2005)

10. Jorge Sa Silva, Tiago Camilo, Pedro Pinto, Ricardo Ruivo, Andre Rodrigues, "Multicast and IP Multicast support in Wireless Sensor Networks", Wireless Pervasive Computing, 2007. ISWPC '07. 2nd International Symposium on, IEEE, (2007)

11. Kiyotaka Oe, Akio Koyama, Leonard Barolli, "Performance Evaluation of a Multicast Routing Protocol for Wireless Mesh Networks Considering Network Load", IEEE 27th International Conference on Advanced Information Networking and Applications, Vol. , No. 4, pp.591-597, (2013)

12. Luo Junhai, Ye Danxia, Xue Liu, and Fan Mingyu, "A Survey of Multicast Routing Protocols for Mobile Wireless Networks", IEEE COMMUNICATIONS SURVEYS \& TUTORIALS, VOL. 11, NO. 1, pp.78-91, (2009)

13. Manish V. Bhosle, Mininath K. Nighot and Somitra S. Das , "An Energy Efficient and Reliable Location wise Data Aggregation In WSN, IEEE International Conference on Computing Communication Control and Automation", pp.322-326, (2015)

14. M. Raj Kumar Naik, Hemant Bhardwaj and P.Samundiswary, "Residual Energy Analysis of DEC and Delivery Ratio Analysis of E-AOMDV protocol for Mobile Sensor Networks", International conference on Communication and Signal Processing, April , 2013, India,pp.509513,IEEE,2013.

15. Mohammad-Amin Kharraz, Hamid Sarbazi-Azad and Albert Y. Zomaya, "On-demand multicast routing protocol with efficient route discovery", ELSVIER journal of Network and Computer Applications,pp.942-950, (2012)

16. Mohamad Nazim Jambli, Kartinah Zen, Halikul Lenando,"Performance Evaluation of AODV Routing Protocol for Mobile Wireless Sensor Network", IEEE 7th International Conference on IT in Asia (CITA), pp.1-6, (2011) 